\title{
Selection of Commercial Robots with Anticipated Cost and Design Specifications using Regression Models
}

\author{
Sasmita Nayak, Neeraj Kumar, B. Choudhury
}

\begin{abstract}
The selection of robots used for industry purpose is a crucial practice where various parameters have to be considered during appropriate selection process. The decision strategy of robot selection has a potential research direction to justify the necessity of industrial needs. We have compared three different mathematical models and selected the best method for choosing the industrial robot to provide a complete selection framework to the present article. Principal Component Regression (PCR), Partial Least Square Regression (PLSR) and Linear Regression using Feed Forward Neural Network (FNN) are the three mathematical models used to correlate input with output parameters. During the testing procedure, eleven numbers of distinct parameters are considered to estimate the best possible rank selection. The strata or rank of the robot is approximated by utilizing the proposed algorithm. However, the most approved rank has met the desired genuinity for a targeted application. In addition to the mathematical methodologies applied here, the performance characteristics for selecting the robot is examined by assessment of statistical errors namely Mean Square Error (MSE), Root Mean Square Error (RMSE), and R-Squared Error (RSE).
\end{abstract}

Keywords: Robot selection, PLSR, FNN, PCR, Selection Framework, Robot parameters.

\section{INTRODUCTION}

In modern engineering and technology robots is the primary tool in a range of developd manufacturing possibilities. The numbers of robot manufacturing units also keep increasing with variable ranges. The task of robot selection from the enormous amount of robots available in the market suitable for a particular application and the production context becomes difficult day by day.

It also focuses on a demand to consider areas like availability, production systems, and economic necessity. Moreover, most of the attributes exhibit paradoxical characteristics and have variable units. Khouja (7) presented the application of Data Envelopment Analysis (DEA) and a multi-attribute decision-making method in first second phase respectively. In cases DEA requires more computation. When the number of factors willingly

Revised Manuscript Received on July 22, 2019.

Sasmita Nayak, Ph.D Scholar, Suresh Gyan Vihar University (SGVU), Jaipur, Rajasthan, India, Email: sasmitacet@ rediffmail.com

Neeraj Kumar, Department of Mechanical Engineering, Suresh Gyan Vihar University (SGVU), Jaipur, Rajasthan, India

B. Choudhury, cDepartment of Mechanical Engineering, Indira Gandhi Institute of Technology (IGIT), Odisha, India. considered by the decision maker is vast and the number of alternative robots are smaller than $\operatorname{DEA}(1,6)$, the out put may be a poor discriminator. Here the author prefers to quote an example of twenty-seven alternative robots

with four attributes for robot selection. Taking the case of the decision maker being unfair with linear programming concepts, DEA may be at a disadvantage in terms of its rationale. Liang and Wang (5) proposed an algorithm for robot selection that was applied to assess decision makers' unfocused evaluations of robot selection factor weightings. The Chu and Lin (8) made a check list of limitations of Liang and Wang (5) method and placed a fuzzy-TOPSIS technique for robot selection. However, the authors had transformed the objective value-factors for selection of robots into fuzzy values that stand against the fundamental rule of fuzzy logic. Moreover, only a 5-point scale was adopted for the rating of robots with respect to their subjective factors. The complicacies of a fuzzy method and its requirement of more processing power are well known. Agrawal et al. (2) presented an approach called 'TOPSIS' for selection of a robot for industrial purpose by assessing four attributes and five alternatives robots. Rao et al. (10) have prepared a digraph and matrix method for robot selection. Agrawal et al. have enlisted four attributes (2) for the given industrial use and five robots have been empanelled. In this paper, the attributes considered are parallel to Agrawal et al. (2), and degree of freedom is of benefit with desirable higher quantitative values. It is doubtless of fact that for lower values are desired for qualitative attributes that can be obtained from the attribute-digraph for robot selection. This method is uneasy if the decision maker is unfriendly with graph theory and matrix method concepts. Babatunji Omoniwa (12) forwarded a Multi-Criteria Robot Selection Problems (MCRSPs) applying Grey Relational Analysis(GRA). Moreover he concluded that the well-defined coefficient has a negligeable effect on GRA that makes more appropriate for exact selection of robot. Chatterjee et.al.(13) resolved two real-time robot selection issues handling visekriterijumsko kompromisno rangiranje (VIKOR) method and Elimination and Choice Expressing Reality (ELECTRE) methods. Parkan and $\mathrm{Wu}$ (9) particularly gave emphasis on a performance

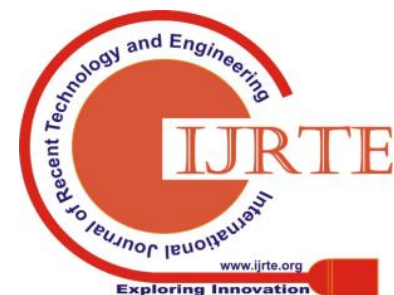


measurement procedure called as operational competitiveness rating (OCRA) and multiple-attribute decision-making method or TOPSIS. The selection was finalised by aggregating and averaging the results of OCRA, TOPSIS, an user friendly model. In this paper, we have proposed the robot selection using the gradient descent with momentum back-propagation algorithm. We have also attempted on the robot determination procedure engaging Partial Least Square Regression (PLSR), Principal Component Regression (PCR) and Linear Regression applied with Feed Forward Neural Network strategy.

\section{MANIPULATOR ATTRIBUTES OF THE INDUSTRIAL ROBOT}

The manipulators play a significant role to specify the potentiality of the robot in a broad range of applications. In most cases, it is an user-need to be supported by classification of logical characteristics of robot so that the confusion in various techniques can be smoothly avoided. If this can make a proper way, then defining a robot for specific applications could be precised. A robot manipulator can specify some quantitative characteristics like payload capacity, horizontal reach, and repeatability and so on. Unfortunately attributes such as built quality, after sales service etc. cannot be expressed quantitatively. Mathematical model and analysis, in some instances, are hepful in defining some other attributes. For instance, to express reliability Mean Time between Failure (MTBF) or Mean Time to Repair (MTTR) methods may be opted. While experimentation shall determine some attributes like life expectancy, the various pertinent attributes assist the user to create a database. The manipulators' attribute types are based on general parameters, physical parameters, performance etc. as given the in Table 1 (A). While making it operational, the capacity to manipulate ("manipulability") can be quantified as manipulability measure.It is used as an attribute. The primary manipulator attributes efficiently used for selection of the robot thus presented.

Table 1 (A). Major types of general selection parameters

\begin{tabular}{|l|c|}
\hline \multicolumn{1}{|c|}{ Parameter } & Type \\
\hline $\begin{array}{l}\text { Price ranges, robot type } \\
\text { and coordinate system }\end{array}$ & General \\
\hline $\begin{array}{l}\text { Actuator type, robot } \\
\text { weight, robot size, } \\
\text { grippers type }\end{array}$ & Physical \\
\hline Workspace and stroke & Performance \\
\hline Type of joints & Structure / Architecture \\
\hline Environment & Applications \\
\hline Safety Features & Sophistication \\
\hline $\begin{array}{l}\text { Joints and } \\
\text { interconnections }\end{array}$ & $\begin{array}{c}\text { Control / feedback } \\
\text { system }\end{array}$ \\
\hline Downtime & Availability / Reliability \\
\hline
\end{tabular}

In this section, we raise a discussion of three aspects of the proposed methodologies for robot selection. In the first part, selection of industrial robots using Partial Least Square Regression (PLSR) is discussed with the result analysis. The second part of the article evaluates the approach of Principal Components Regression (PCR). Finally, performance of Linear Regression using Feed Forward Neural Network scheme is discussed with comparative analysis between three robot selection approaches.

\subsection{Robot Selection using Partial Least Square Regression (PLSR) scheme}

Modern robot assurance models are awesome value systems that can be comprehended applying solid estimation techniques such as different linear regression samples. In this work, PLSR is forwarded for the selection of industrial robots using various manipulator attributes. A PLSR model is set using robot specification attributes that produces the desired robot rank [14]. PLSR can be an extension from the various linear regression models [12]. To use most clear edge, an immediate model shows the (linear) association between a dependent (response) variable ' $\mathrm{F}$ ', and manupulator attributes, the M's, all together that can be represented as in equation 1 .

$$
\mathrm{F}=\mathrm{c} 0+\mathrm{c} 1 \mathrm{M} 1+\mathrm{c} 2 \mathrm{M} 2+\ldots+\mathrm{cpMp}
$$

According to the equation 1, the parameters, for example, $\{\mathrm{c} 0, \mathrm{c} 1, \ldots . . \mathrm{cp}\}$ are denoted as regression coefficients. The relapse coefficients are denoted as $\mathrm{M}$, where $\mathrm{M}=\{\mathrm{c} 0, \mathrm{c} 1$, ....cp \} and the PLSR's performance capacity is assessed from the matrix (F'MM'F) [15, 17]. Robot selection procedure is evaluated and the result for robot rank is materialized in figure 1.

\subsection{Robot Selection using Principal Components Regression (PCR) Scheme}

Principal component regression (PCR) is also a regression analysis methodology which is similar to Principal Component Analysis (PCA) [15]. This regression model continuously analzes the results over a set of independent variables (designated as covariants). This regression model stands on a linear regression representation like PCA and it provides regression coefficients similar to PLSR one [16]. The generic regression equation can be presented as below.

Where,

$\mathrm{R}=$ Dependent Variable

$\mathrm{I}=$ Independent Variables

$\mathrm{C}=$ Regression Coefficients which needs to be estimated err $=$ errors or residuals during the estimation procedure

$$
\text { - (2) }
$$




\subsection{Robot Selection using Linear Regression using Feed Forward Neural Network Scheme}

The proposed scheme is based on generalized linear regression mechanism but the regression coefficients are adjusted using Feedforward Neural Network (FNN) model. The FNN is a simple type of neural network scheme which is largely used to train mathematical models. It does not contain any cycles or loops to train the model. The FNN model trains its weights according to the input and target parameters supplied to it during the model training. As per the generalized neural network model, it contains numbers of hidden layers where inputs and target parameters are connected to it.

\subsection{Parameters used for the proposed robot Selection of procedure}

By and large, a practical robot wants a base particular that is to be chosen relying upon the ideal relevance. The choice method needs few info distinguished characteristics or parameters as recorded in the table 1 (B). They are the base essentials for practically epitomized applications in present industrial robot selections.

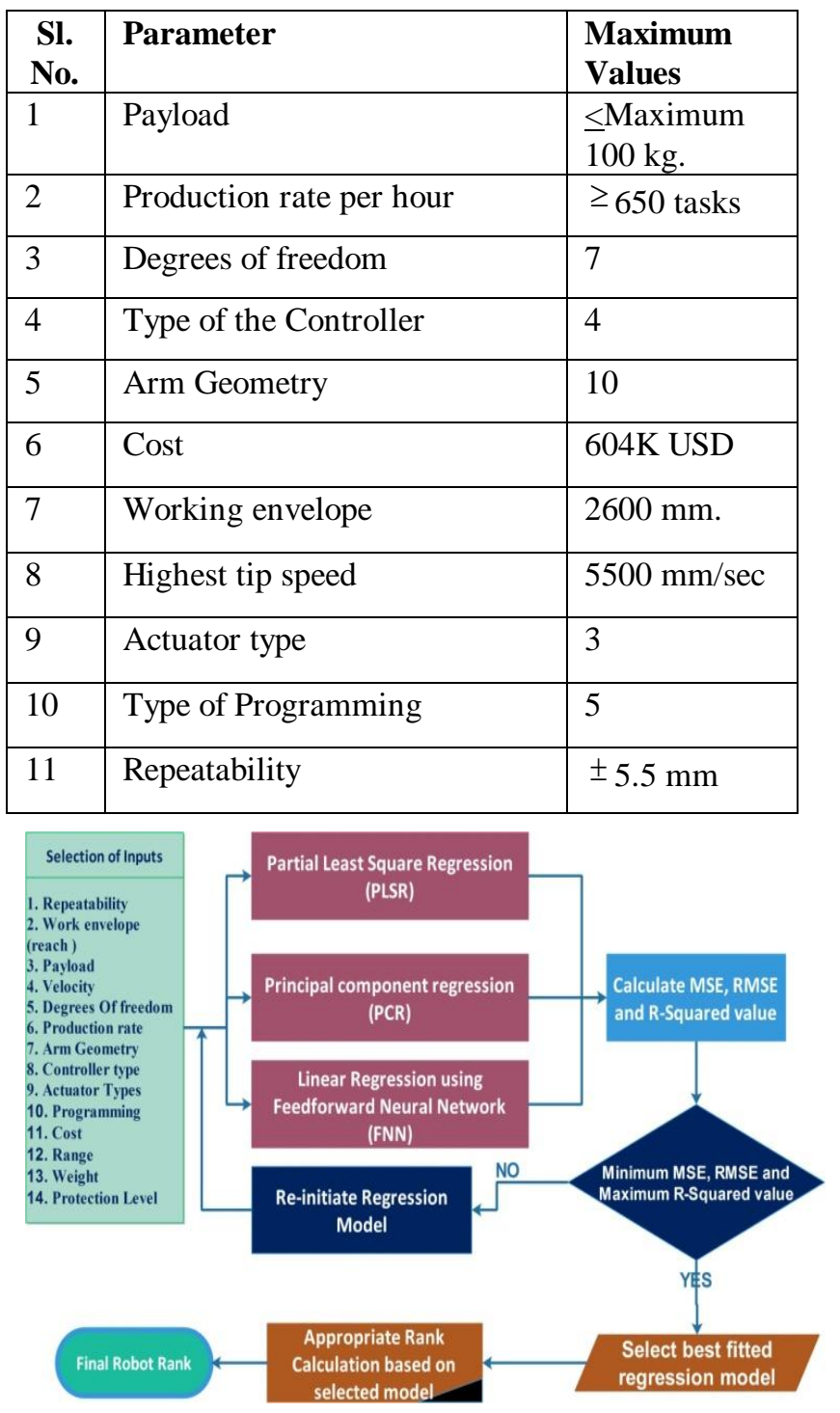

Figure 1 presents the entire strategy of selection of robot rank in a workflow diagram. In this research paper, we have proposed a generalized or less specialized robot ranking rating chart with reference to assessment of the usual specifications for each robotic rank. Further, 11 numbers of distinct elements are taken into account with values keeping pace with economic necessities. The result depicts the robot rank. The proposed robot rank is limited to ten distinct classes as shown in table 2 (A) and 2 (B).

Table 2 (A). Proposed Ranking scheme of the Industrial Robots

\begin{tabular}{|c|c|c|c|c|c|c|c|c|c|c|c|c|}
\hline $\begin{array}{l}\text { SI. } \\
\text { No. }\end{array}$ & $\begin{array}{l}\text { Name of Robot } \\
\text { Parameter }\end{array}$ & Unit & $\begin{array}{l}\text { Rank } \\
1\end{array}$ & \begin{tabular}{|l} 
Rank \\
2
\end{tabular} & $\begin{array}{l}\text { Rank } \\
3\end{array}$ & $\begin{array}{l}\text { Rank } \\
4\end{array}$ & \begin{tabular}{|l|} 
Rank \\
5
\end{tabular} & $\begin{array}{l}\text { Rank } \\
6\end{array}$ & \begin{tabular}{|l} 
Rank \\
7
\end{tabular} & $\begin{array}{l}\text { Rank } \\
8\end{array}$ & $\begin{array}{l}\text { Rank } \\
9\end{array}$ & \begin{tabular}{|l} 
Rank \\
10
\end{tabular} \\
\hline 1 & Work envelop & $\mathrm{mm}$ & $\begin{array}{l}550 . \\
00\end{array}$ & $\begin{array}{l}1050 . \\
00\end{array}$ & $\begin{array}{l}1550 . \\
00\end{array}$ & $\begin{array}{l}2050 . \\
00\end{array}$ & $\begin{array}{l}2150 . \\
00\end{array}$ & $\begin{array}{l}2250 . \\
00\end{array}$ & $\begin{array}{l}2350 . \\
00\end{array}$ & $\begin{array}{l}2450 . \\
00\end{array}$ & $\begin{array}{l}2550 . \\
00\end{array}$ & $\begin{array}{l}2700 . \\
00\end{array}$ \\
\hline 2 & $\begin{array}{l}\text { Velocity } \\
\end{array}$ & $\begin{array}{l}\mathrm{mm} / \\
\mathrm{s}\end{array}$ & $\begin{array}{l}550 . \\
00\end{array}$ & $\begin{array}{ll}1000 \\
00\end{array}$ & $\begin{array}{l}1550 . \\
00\end{array}$ & $\begin{array}{l}2000 . \\
00\end{array}$ & $\begin{array}{l}2550 . \\
00\end{array}$ & $\begin{array}{l}3050 . \\
00\end{array}$ & $\begin{array}{l}3550 . \\
00\end{array}$ & $\begin{array}{l}4000 . \\
00\end{array}$ & $\begin{array}{l}4550 . \\
00\end{array}$ & $\begin{array}{l}5000 . \\
00\end{array}$ \\
\hline 3 & Cost & $\begin{array}{l}\text { USD } \\
\text { (S) }\end{array}$ & $\begin{array}{l}100 . \\
00\end{array}$ & $\begin{array}{l}200.0 \\
0\end{array}$ & $\begin{array}{l}250.0 \\
0\end{array}$ & $\begin{array}{l}300.0 \\
0\end{array}$ & $\begin{array}{l}350.0 \\
0\end{array}$ & $\begin{array}{l}400.0 \\
0\end{array}$ & $\begin{array}{l}450.0 \\
0\end{array}$ & $\begin{array}{l}500.0 \\
0\end{array}$ & $\begin{array}{l}550.0 \\
0\end{array}$ & $\begin{array}{l}600.0 \\
0\end{array}$ \\
\hline 4 & Arm Geometry & Nos. & 1.00 & 1.00 & 2.00 & 2.00 & 2.00 & 2.00 & 3.00 & 3.00 & 4.00 & 4.00 \\
\hline 5 & Actuator Types & No5. & 1.00 & 2.00 & 2.00 & 3.00 & 3.00 & 4.00 & 4.00 & 5.00 & 5.00 & 5.00 \\
\hline 6 & $\begin{array}{l}\text { Maximum } \\
\text { Operating Range }\end{array}$ & $\begin{array}{l}\text { mete } \\
r\end{array}$ & 1.00 & 2.00 & 3.00 & 4.00 & 5.00 & 6.00 & 7.00 & 8.00 & 9.00 & 10.00 \\
\hline 7 & Protection level & Nos. & 0.00 & 1.00 & 2.00 & 3.00 & 4.00 & 5.00 & 6.00 & 7.00 & 8.00 & 9.00 \\
\hline 8 & $\begin{array}{l}\text { Degrees } \\
\text { freedom }\end{array}$ & Nos. & 1.00 & 2.00 & 3.00 & 5.00 & 5.00 & 6.00 & 6.00 & 7.00 & 7.00 & 7.00 \\
\hline 9 & Production rate & $\begin{array}{l}\text { Task/ } \\
\text { hour }\end{array}$ & 1.00 & 2.00 & 3.00 & 3.00 & 4.00 & 4.00 & 4.00 & 4.00 & 4.00 & 4.00 \\
\hline 10 & Programming & Nos. & 7.55 & 15.10 & 30.20 & 45.30 & 60.40 & 75.50 & $\begin{array}{l}151.0 \\
0\end{array}$ & $\begin{array}{l}302.0 \\
0\end{array}$ & $\begin{array}{l}453.0 \\
0\end{array}$ & $\begin{array}{l}604.0 \\
0\end{array}$ \\
\hline 11 & Body Weight & $\mathrm{Kg}$ & $\begin{array}{l}20.0 \\
0\end{array}$ & 30.00 & 40.00 & 50.00 & 60.00 & 70.00 & 80.00 & 90.00 & $\begin{array}{l}100.0 \\
0\end{array}$ & $\begin{array}{l}110.0 \\
0\end{array}$ \\
\hline 12 & Repeatability & $\pm \mathrm{mm}$ & 5.50 & 5.50 & 4.50 & 4.00 & 3.50 & 3.00 & 2.50 & 2.00 & 1.50 & 1.50 \\
\hline 13 & Payload & $\mathrm{Kg}$ & $\begin{array}{l}15.0 \\
0\end{array}$ & 25.00 & 35.00 & 45.00 & 55.00 & 65.00 & 75.00 & 85.00 & 90.00 & $\begin{array}{l}1110.0 \\
0\end{array}$ \\
\hline 14 & Controller type & Nos. & 1.00 & 1.00 & 1.00 & 2.00 & 2.00 & 2.00 & 3.00 & 3.00 & 3.00 & 3.00 \\
\hline
\end{tabular}

Table 2 (A). Proposed Ranking scheme of the Industrial Robots

\begin{tabular}{|c|c|c|c|}
\hline $\begin{array}{l}\text { Sl. } \\
\text { No. }\end{array}$ & Attributes & $\begin{array}{c}\text { No. of } \\
\text { Sub- } \\
\text { categories }\end{array}$ & Different Sub-categories with their index \\
\hline 1. & $\begin{array}{l}\text { Controller } \\
\text { type }\end{array}$ & 4 & $\begin{array}{ll}\text { 1. Non-servo } \\
\text { 2. Servo Point-to-Point } \\
\text { 3. Servo Continuous Path } \\
\text { 4. Combined PTP and CP }\end{array}$ \\
\hline 2. & $\begin{array}{l}\text { Am } \\
\text { Geometry }\end{array}$ & 10 & $\begin{array}{l}\text { 1. Spherical light } \\
\text { 2. Spherical Medium } \\
\text { 3. Articulated light } \\
\text { 4. Articulated Medium } \\
\text { 5. Rectangular light } \\
\text { 6. Cylindrical light } \\
\text { 7. Rectangular Medium } \\
\text { 8. Cylindrical Medium } \\
\text { 9. Rectangular Heavy } \\
\text { 10. Cylindrical Heavy } \\
\end{array}$ \\
\hline 4. & $\begin{array}{l}\text { Actuator } \\
\text { Types }\end{array}$ & 3 & $\begin{array}{ll}\text { 1. Hydraulic } \\
\text { 2. Electric } \\
\text { 3. Pneumatic }\end{array}$ \\
\hline 3. & Programming & 5 & $\begin{array}{ll}\text { 1. } & \text { Task-oniented Program } \\
\text { 2. } & \text { Off-line Program } \\
\text { 3. } & \text { On-line Program } \\
\text { 4. } & \text { Teach-pendant Program } \\
\text { 5. } & \text { Lead through teach Program }\end{array}$ \\
\hline
\end{tabular}

TABLE 2 (B). Proposed subcategories of the different attributes of robot 


\section{Selection of Commercial Robots with Anticipated Cost and Design Specifications using Regression Models}

\section{RESULTS AND DISCUSSION}

Three algorithms are tested with standard data sets and the predicted industrial robot ranks are evaluated with 14 numbers of distinct robot parameters. Several research articles have considered only 10 numbers of robot parameters but approximaed standard cost, operating range, protection level and weight are not included in the selection procedure. In this article almost all the robot selection parameters are considered in the robot selection procedure. The rediction performance of three dinstinct algorithms like PLSR, PCR and Linear Regression using Feed Forward Neural Network (FNN) are evalued successfully. The prediction performance is dipicted in the figure 2. It can be observed from the figure 2 that the rank prediction using PLSR has better predictability and easy to implement mathematically. The PLSR coeeficients are also evaluated which is shown in the equation 3 .

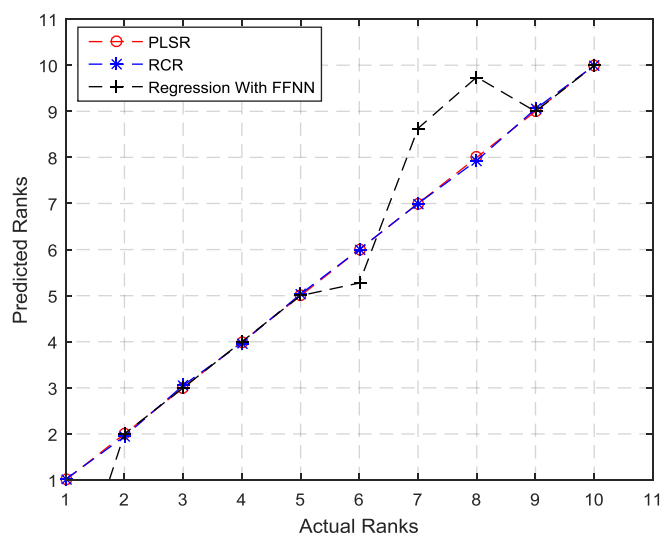

The model equation obtained during PLSR testing is defined the equation 3 .

Rank of the Robot $=(-203417 \mathrm{e} 8)+[(33902 \mathrm{e} 8) \times$ Repeatability]

$+[(3.14942 \mathrm{e}-06) \times$ Work envelop $+[(-672940 \mathrm{e} 8) \times$ Payload $]$

$+[(13628 \mathrm{e} 8) \times$ Velocity $]$

$+[(-0.8569) \times$ Degrees of freedom $]+[(0.01447) \times$ Rate of Production]

$+[(-67805 e 8) \times$ Index of Arm Geometry $]+[(0.7765) \times$ Type of Controller]

$+[(0.5727) \times$ Index of the type of Actuator $]+[(0.3436) \times$ Index of Programming]

$+[(-0.005751) \times$ Cost $]+[(0.0044) \times$ Range $]+[(0.0440) \times$ Weight $]+[(-0.0044) \times$ Index of the level of Protection $]$ (3)

The mathematical model that is procured during PCR is specifically explained in equation 4 . It can be observed from equation 4 that the three parameters such as Range, Weight and Protection Index has no effect on the rank prediction sheme. But the performance of PCR scheme in the rank prediction methodology has more error magnitude.

Rank of the Robot $=(-0.03460)+[(-1.8760 \mathrm{e}-06) \times$ Repeatability $]+[(0.0001223) \times$ Work envelop $]+$ 3.75210e-05) $\times$ Payload]

$+[(0.0018760) \times$ Velocity $]+[(1.4263463 e-06) \times$ Degrees of freedom $]+[(0.0001741) \times$ Rate of Production $]$

$+[(3.7521051 \mathrm{e}-06) \times$ Index of Arm Geometry $]+$ [(1.4972e-06) $\times$ Type of Controller]

$+[(6.3964063 \mathrm{e}-07) \times$ Index of the type of Actuator $]+$ $[(1.8730 \mathrm{e}-06) \times$ Index of Programming $]$

$+[(0.0004310) \times$ Cost $]+[(0) \times$ Range $]+[(0) \times$ Weight $]+$ [(0) $\times$ Index of the level of Protection]

Furher, the residual error of three rank prediction methodologies are evaluated which is presented in figure 3. It shows that PLSR scheme has minimum error for all the 10 numbers of ranks but the other two schemes has significant amount of error magnitudes. Therefore, PCR and Regression with FNN cannot be considered for actual implementation of industrial robot selection process

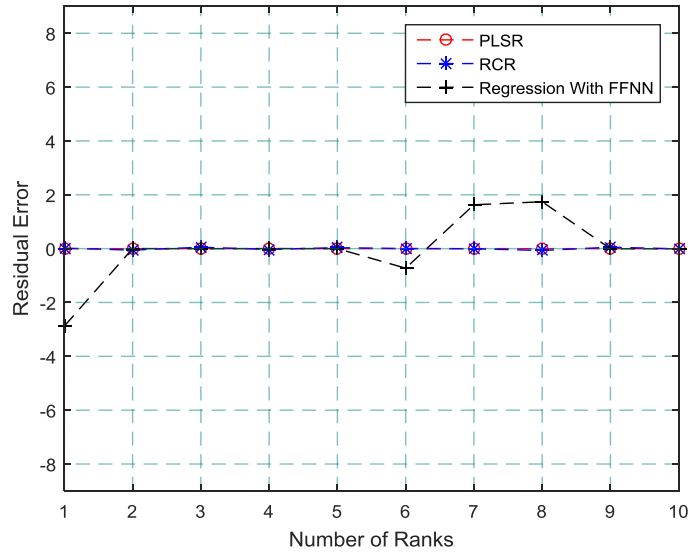

Figure.3. Residual error of three rank prediction schemes

In the similar context, the error band also evaluated for three rank preiction schemes which is shown in the figure 4 .

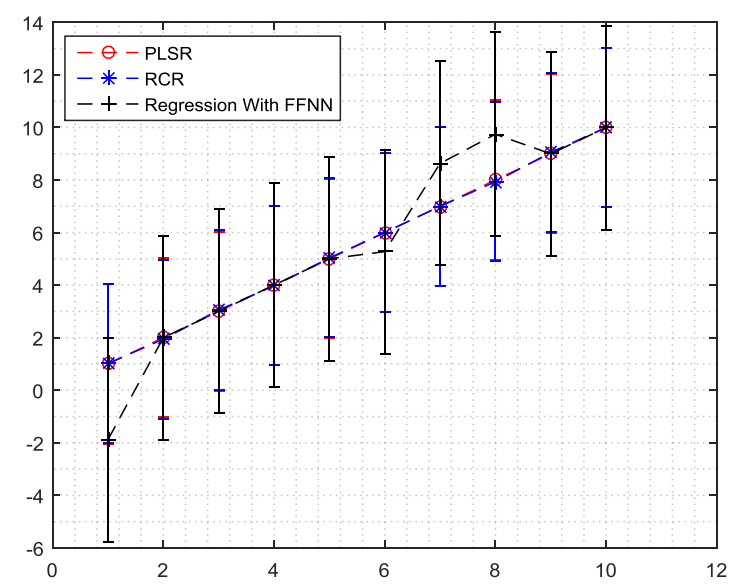

Figure.4. Error band of three rank prediction schemes 


\begin{tabular}{|c|c|c|c|}
\hline $\begin{array}{c}\text { Proposed Rank } \\
\text { Prediction Algorithms }\end{array}$ & MSE & RMSE & R-squared \\
\hline PLSR & $9.5869 \mathrm{e}^{-15}$ & $9.3214 \mathrm{e}^{-29}$ & 0.9999 \\
\hline PCR & $12.5876 \mathrm{e}^{-9}$ & $11.94321 \mathrm{e}^{-12}$ & 0.8899 \\
\hline Regression using FNN & 1.1942 & 1.3701 & 0.8831 \\
\hline
\end{tabular}

Table 3. Level of Errors obtained from the proposed Robot Ranking Prediction techniques

The error like MSE, RMSE and R-Squared values are calculated during the testing of robot rank prediction scheme. The individual errors of all the three prediction methodologies are enlisted in table 3. It can be measured out that PLSR scheme produces least MSE, RMSE and maximum R-Squared value which is acceptable for the implementation of the robot rank prediction methodology. Furthermore, few test data are taken to evaluate the performance of the indivisual rank prediction methologies which is shown in the following.

\begin{tabular}{|c|c|c|}
\hline Test Parameters & $\begin{array}{c}\text { Test Parameter } \\
\text { Values }\end{array}$ & $\begin{array}{c}\text { Predicted Rank } \\
\text { using three } \\
\text { algorithms }\end{array}$ \\
\hline Work-envelop & 2050.00 & \multirow{14}{*}{$\begin{array}{l}\text { Actual Rank }=4 \\
\text { Rank Using PLSR = } \\
4 \\
\text { Rank Using PCR = } \\
\text { Rank Using Linear } \\
\text { Regression through } \\
\text { Feed Forward Neural } \\
\text { Network =3 }\end{array}$} \\
\hline Payload & 45.00 & \\
\hline Velocity & 2000.00 & \\
\hline Degrees Of freedom & 5.00 & \\
\hline Arm Geometry & 3.00 & \\
\hline Type of Controller & 2.00 & \\
\hline Programming & 3.00 & \\
\hline Cost & 45.30 & \\
\hline $\begin{array}{l}\text { Maximum Operating } \\
\text { Range }\end{array}$ & 4.00 & \\
\hline $\begin{array}{c}\text { Weight of the Robot } \\
\text { Body }\end{array}$ & 50.00 & \\
\hline Level of Protection & 3.00 & \\
\hline Repeatability & 4.00 & \\
\hline Type of Actuator & 2.00 & \\
\hline Rate of Production & 300.00 & \\
\hline
\end{tabular}
methodology

We have seen that our proposed strategy is significantly solid and produces subjective impacts conversely with various posted strategies. In other research articles, the system utilizes least wide assortment of parameters when contrasted to the prediction model as propsed by us. Thus to the said certainties, our proposed technique adds additional probability, reasonable and notwithstanding simple robot choice strategy by method of considering greatest quantities of the most significant automated determination parameters.

\section{V.CONCLUSION}

To quote, the present automation is performed usefully with the methodology proposed in this paper by taking explicit mechanical robot parameters. Through it, at the most extreme, 14 numbers of parameters are clearly considered as a commitment for the choice method of robotics. The ranks of the well known industrial robot is evaluated flawlessly which demonstrates the best real benchmark. The carrying out test
Table 4.Test inputs and estimated rank using the proposed

of proposed approach for PLSR is assessed by means of discovering MSE, RMSE, and R-squared blunders. Procured errors amidst assurance exhibits that the execution of PLSR model provides a superior outcome of determining current rank of robot. The MSE and RMSE gained by the said calculations are $9.5869 \mathrm{e}-15,9.3214 \mathrm{e}-29$ respectively. In a comparative sense, PCR model and Linear Regression using FNN are additionally utilized with a similar robot detail information and the exhibition is considered. From the investigation results, it is seen that PCR and Linear Regression using FNN are not upto the mark of robot selection using PLSR. Thus, in comparision to other running structures, it is inferred that PLSR framework for the decision of industrial robot conveys favored desired result .

\section{REFERENCES}

[1]. R.P. Paul, and Shimon Y. Nof, "Work Methods Measurement: A Comparison Between Robot and Human Task Performance",Taylor\&Francis,IFPR, Volume:17, Issue:3, Pages:277-303, 1979.

[2]. V.P. Agrawal and V.Kohli, S. Gupta, "Computer-Aided Robot Selection: the Multiple-Attribute Decision Making an Approach",International Journal of Production Research, Volume:29, Issue:8, Pages: 1629-1644, 1991.

[3]. ŞenimÖzgürler, Ali F. Güneri,BahadırGülsün, OnurYılmaz,"Robot Selection for a Flexible Manufacturing System with AHP and TOPSISMethod", 15th International Research Conference on TMT-2011, Prague, Czech-Republic, 2011.

[4]. M.Z. Rehman, N.M. Nawi, "The Effect of Adaptive Momentum in Improving Accuracy of Gradient Descent Backpropagation Algorithm on Classification Problems", Springer-Verlag, Volume:179, Pages: 380-390, 2011.

[5]. G.H. Liang, and M.J. Wang, "A Fuzzy Multicriteria Decision-Making Approach for Robot Selection",Robotics, and Computer-Aided Manufacturing, Volume:10, Pages: 267-274, 1993.

[6]. M. Vukobratovic, "Scientific Fundamentals of Industrial Robots1: Dynamics of Manipulator Robots Theory and Applications",Springer-Verlag Publication, New York, 1982.

[7]. M. Khouja, "The Use of Data Envelopment Analysis for Technology Selection”, Computer Industrial Eng., Volume:28, Pages: 123-132, 1995.

[8]. T.C. Chu, and Y.C. Lin, "A Fuzzy-TOPSIS Method for Robot Selection",International Journal of Advanced Manufacturing Technology, Volume:21, Pages: 284-290, 2003.

[9]. C. Parkan, M.L. Wu, "Decision-Making and Performance Measurement Models with Applications to Robot Selection",Computer Industrial. Eng., Volume:36, Issue:3, Pages: 503-523, 1999.

[10]. R.V. Rao, K.K. Padmanabhan, "Selection, Identification and Comparison of Industrial Robots Using Digraph andMatrix Methods",Elsevier, Robotics, and Computer Integrated Manufacturing, Volume:22, Issue:4, Pages: 373-383, 2006.

[11]. SuprakashMondal, S.Chakraborty, "A Solution to Robot Selection Problems Using Data Envelopment Analysis", International Journal of Ind. Eng. Computations, Volume:4, Issue:3, Pages:355-372, 2013.

[12]. Varun K. Nagaraja,Wael Abd-Almageed, "Feature Selection using Partial Least Squares regression and optimal experiment design", International Joint Conference on Neural Networks (IJCNN), Pages:1-8, 2015.

[13].Chu TC, Lin YC, "A fuzzy TOPSIS method for robot selection", International Journal of Advanced Manufacturing Technology, Volume 21, pages: 284-290, 2003.

[14]. Nicole Kr"amer, Masashi Sugiyama, The Degrees of Freedom of Partial Least Squares Regression, Journal of the American Statistical Association, Page: 1-23, 2011.

[15]. B. Efron, The Estimation of Prediction Error: Covariance Penalties and Cross-Validation. Journal of the American Statistical Association, 99(467):619-633, 2004. 
[16].I. Frank, and J. Friedman, A Statistical View of Some Chemometrics Regression Tools. Technometrics, 35(2):109-135, 1993.

[17]. Carsten Neumann, Michael Förster, Birgit Kleinschmit, SibylleItzerott, Utilizing a PLSR-Based Band-Selection Procedure for Spectral Feature Characterization of Floristic Gradients, IEEE Journal of Selected Topics in Applied Earth Observations and Remote Sensing, Volume: 9, Issue: 9 , Pages:3982 - 3996, Sept. 2016.

[18]. Nayak S., Choudhury B.B., Lenka S.K. Gradient Descent with Momentum Based Backpropagation Neural Network for Selection of Industrial Robot. In: Satapathy S., Das S. (eds) Proceedings of First International Conference on Information and Communication Technology for Intelligent Systems: Volume 1. Smart Innovation, Systems and Technologies, vol 50. Springer, 2016. 